\title{
Role of sustainomics and external climate forcing mechanism in biodiversity extinction : An overview
}

\begin{abstract}
Neerja Upadhyaya*
Department of Chemistry, S.S. Jain Subodh Girls College, Sanganer, Jaipur - 302011 (Rajasthan), India

Ruchi Jain

Department of Chemistry, S.S. Jain Subodh Girls College, Sanganer, Jaipur - 302011

(Rajasthan), India

R. Upadhyaya

SBM-St Xaviers, Bangalore, Karnataka, India

${ }^{*}$ Corresponding author. E-mail: upadhyayaneerja@gmail.com

Abstract

Over millions of years, physiology and anatomy of the living organisms has been changed due to internal climate forcing mechanism. This has influenced the world wide distribution of species. External climate forcing mechanism has caused rapid rise in earth's temperature and it is expected to rise by $2-4{ }^{\circ} \mathrm{C}$ by the end of the century. It has now been recognised as the most complex problem of present scenario and being concerned in almost every field of science. Climate change is the most sensitive issue which is a challenge not only for the government and society but also for each individual. In the present communication impact of external climate forcing mechanism on biodiversity and its extinction is being analysed and role of sustainomics for the same is overviewed. Studies reveal that the rate of speciation of flora and fauna is not in the accordance with the rate of externally enforced climate change. Thus, the increased rate of climate change has caused catastrophic mass extinction threat for plants, animals and insects in the anthrapocene era. The pattern of extinction and threatened species are not yet known. Various solutions for the problem have been suggested by the multidisciplinary researches, rooted by the sustainomics. These suggestions include to diverge from fossil fuel, to use renewables, to make and apply rules for 3 Rs etc. Only cooperative involvement of social, scientific and industrial bodies may resolve the problem.
\end{abstract}

Keywords: Biodiversity Extinction threat, External climate forcing mechanism, Speciation, Sustainomics

\section{INTRODUCTION}

Biodiversity is invariably significant but facing danger enforced by the climate change. Climate change is the most threatening global challenge for the humanity (Jonathan 2016). This issue becomes more prominent for the countries which are encompassed in climatic and geological conditions which make them rich in biodiversity. India also belong to the same class and has wide range of biodiversity including marine, Himalayan, desert, indo-gangatic and panasual ecosystem.

Adverse effects of climate change on ecosystem had lead to numerous investigations and publications in the related disciplines (Munasinghe 2010; Pimm 2008). Such studies support that rate of climate change has increased drastically as a consequence of urbanization and industrial development. In the recent timeframe every man is contributing to this threat which has caused global

\section{Article Info}

DOI: 10.31018/jans.v11i1.2009 Received: February 6, 2019 Revised: February 28, 2019 Accepted: March 2, 2019

\section{How to Cite}

Upadhyaya, N. et al. (2019). Role of sustainomics and external climate forcing mechanism in biodiversity extinction : An overview. Journal of $A p$ plied and Natural Science, 11(1): 223-226 warming. Combustion of fossil fuel emits near about 40 billion metric tons of carbon dioxide every year. Even agriculture is the third largest source of carbon dioxide, emission after burning of fossil fuel and transportation, which cannot be reduced in order to fulfil the requirement of food. Global contribution of this sector to carbon dioxide emission is increased by about 15\% (nearly 5 billion tons per year) in the last two decades (Quéré et al. 2018, Figueres et al., 2018, Jackson et al., 2018).

External climate forcing mechanism: Internal climate forcing includes natural changes imposing climate variability. External forcing mechanism is the topic of concern as it has hazardously increased the rate of climate change. Conventional industrial resources and urbanization are prominent external forces. Consumption of fossil fuel emits green house gases. Such practices result in the disturbances in carbon, nitrogen and water cycles. This has been recognized as the dominat- 


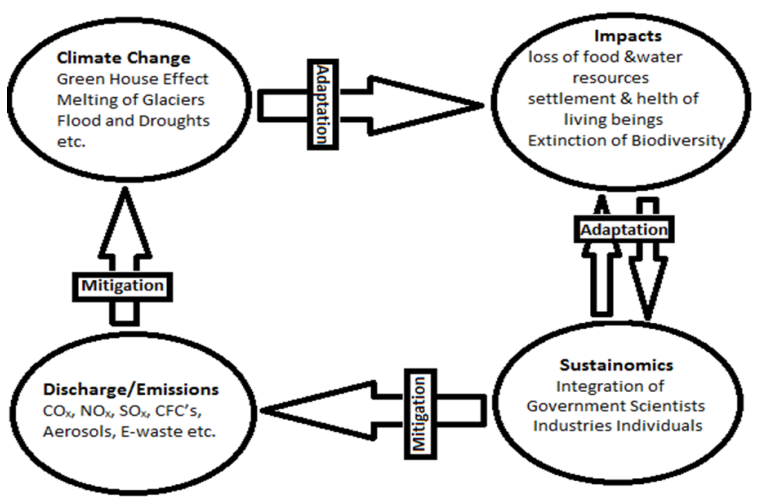

Fig. 1. Role of Sustainomics and Climate Change in Extinction of Biodiversity (Based on IPCC 2001).

ing factor for global warming. Along with green house effect, ozone layer depletion has also witnessed the effect of external forces, including deforestation, use of synthetic harmful chemicals like aerosols, petrochemical based products etc., on climate change. These have imposed unnatural changes in geological, chemical, physical environment which have enforced rapid climate variation, resulting in frequent and unpredicted natural disasters like cyclone, droughts, heat stroke etc. thus, climate change has been recognised as one of the major threats for biodiversity. Studies reveal that about 27000 species are endangered because of changing climatic conditions (Hui, 2013). Climate change, extinction of biodiversity and role of sustainomics: Biodiversity means worldwide distribution of flora and fauna. Migration of organisms over a period of time and their adaptation and immigration has enriched the biodiversity but externally encouraged rapid climate change has endangered numerous species ranging from insects to vertebrates. Although species get modified and migrate according to climate change but still extinction is being predicted and expected because the increased rate of climate change has increased required rate of immigration. But immigration speed of organisms is about one tenth of the required speed (Dominique B. et al. 2010).

Thus, increasing rate of climate change has led to the rate of extinction of biodiversity also and by controlling the rate of climate change rate of extinction can be controlled. Relation between climate change, biodiversity and sustainomics is shown in fig. 1.

Overall extinction rate for vertebrates including birds, amphibians and mammals has been approximately tripled in the last century and the number of endangered species has also been doubled to tripled (Anonymous 2010, Birdlife International 2014, Schipper et al. 2008, Stuart et al. 2004). Climate change is recognised as major cause for the same (Chandrakar et al. 2016). The range of estimate for the extinction rate due to climate change is wider ranging from $15 \%$ to $37 \%$ for various taxa (Thomas et al. 2004). More than

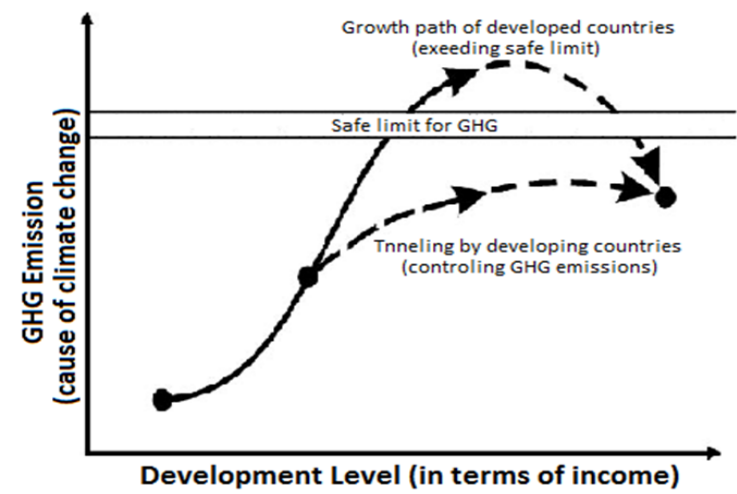

Fig. 2. Two ways for climate change control : (i) reduced GHG emission in developed countries and (ii) alternate development path with low GHG emission for developing countries. Source : (Munasinghe, 2002).

400 species ( $4.6 \%$ of 8750 studied species) are expected to commit extinction by the year 2050 (Jetz et al., 2007). Studies on climate induced changes in western hemisphere predicted extinction of land birds ranging from $1.3 \%$ to $30 \%$ for studied species (3349) for temperature rise from 2.1C to $6.4 \mathrm{C}$ (Sekercioglu et al., 2008).

Marine fisheries and invertebrates are also facing danger. Also due to acidification of sea water (Frithjof et al., 2017, Parker et al., 2013). The temperature rise, acidification and increase in water level have threatened coral reef also (Frithjof et al., 2017, Done, 2003). Extinction threats are Poleward range movements would also lead to the extinction of species in tropical region (4\%) and sub polar latitudes $(7 \%)$ (Thomas et al., 2004). Terrestrial species are also endangered due to rapid climate change (IUCN red list 2018) (Pimm 2008). About 7 to $24 \%$ of the global vegetation is also predicted to face extinction in the coming era (IUCN red list 2018) (Malcolm et al. 2006, Van Vuuren 2006). Studies revealed rate of climate forced extinction of biodiversity varies from species to species and depends upon climatic and ecological conditions also. Expected extinction rate in marine ecosystems is lower than the terrestrial ecosystems because of grater possibilities of migration of organisms in the water (Chandrakar et al. 2016).

Eco-evolutionary framework may also help in understanding immigration and adaptation of species and in biodiversity conservation. Sustainomics got its roots in the last decade in the twentieth century and developed continuously. Last two decades have witnessed several national and international responses to control external climate forcing mechanisms. These responses include entrance of UNFCCC (United Nations' Framework Conservation on Climate Change) and Kyoto Protocol to the force, Cancun agreements etc (Soni et al. 2017). Initiatives taken by Inter Governmental Science - Policy Platform on Biodiversity and eco- 
system services (IPBES) are additive to the knowledge and promoting to the sustainable ways to reverse the problem. IPBES has been adopted as science-policy interface by several biodiversity related conventions like Convention on Biodiversity (CBD) (UN decade on biodiversity press release 2018). Some of the international responses to control and reduce climate change are listed in Table 1.

Availability of ample of data motivates efforts to prevent endangered species. If emission of carbon dioxide is stopped by the immediate effect, even then its level and consequently the temperature elevation is expected to remain constant for the centauries. Expansion of related information is essential for reducing and reverting main made path of climate change for biodiversity extinction. Global level, national level and sactorial and project level integration to minimise the problem include adaptation and mitigation responses, inte-

Table 1. International responses to support and develop sustainomic framework, to reduce rate of climate change and extinction of biodiversity.

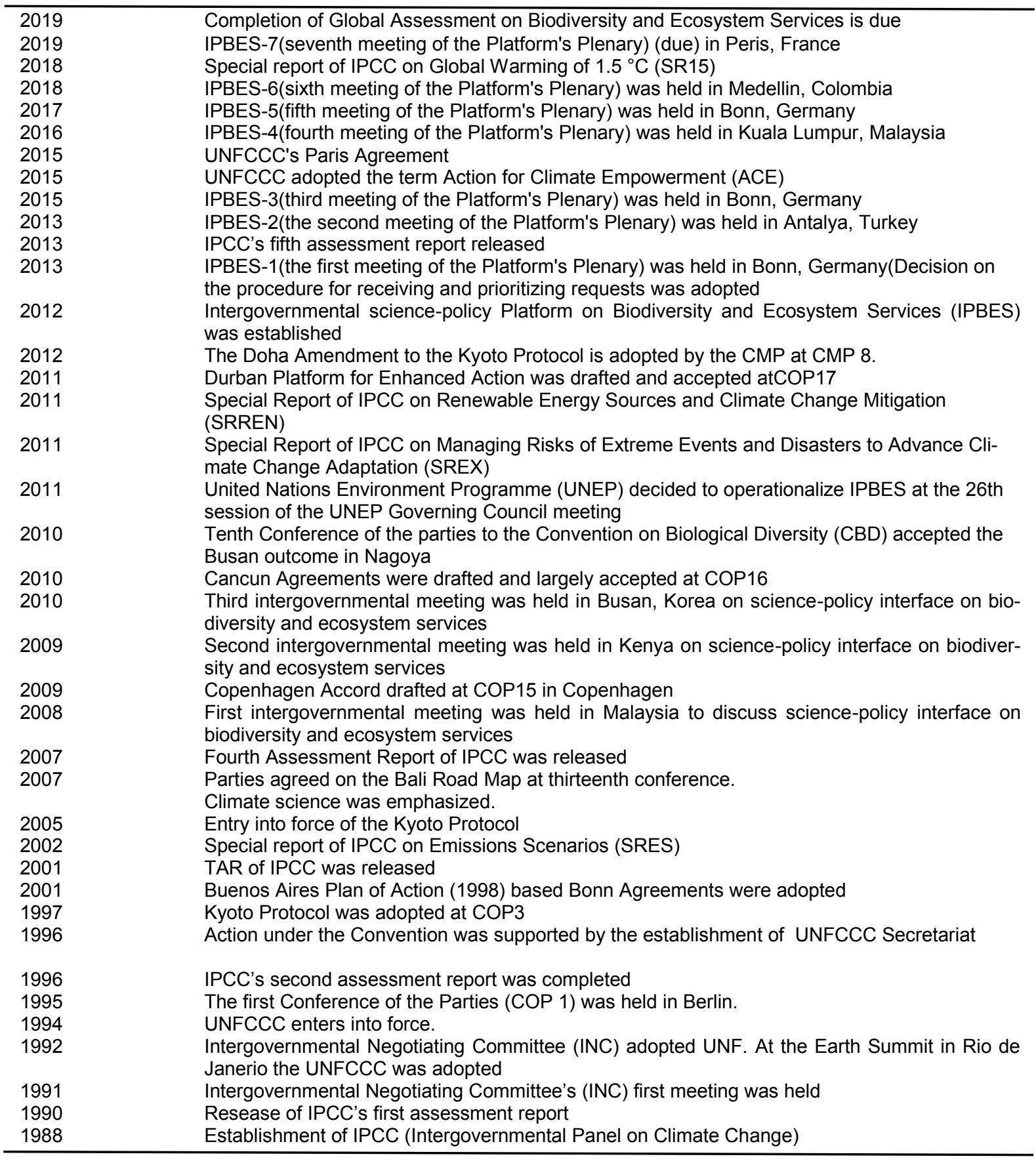


gration of consumer and producer responses, macro environmental analysis, sustainable energy pricing, Kyoto flexibility mechanisms, action impact matrix, agriculture, water and food security, multi criteria analysis and to promote use of renewable energy resources (Munasinghe, 2009).

Developed countries have crossed the safe limit of green house gases (GHG) emission throughout the development and according to estimation emission of GHG is on the peak which is expected to go down with the further development. For developing countries it's an alarming stage and it is the time to tunnel through the growth path of developed countries (Munasinghe 2002) Fig 2.

\section{Conclusion}

Impact of climate change on biodiversity is complex to understand and explain. Although the effect of climate variation seems to be prolonged, but requires immediate and effective reversal because of high climate change inertia. Various development solutions based on sustainomics have been discussed above. Now, necessity is of positive implementation of these suggestions by the government, scientists and society. Both the common people and industrial bodied of developed and developing countries must be abided promisingly with the intergovernmental and science policies to make the development sustainable.Ultimately almost all the sustainomics ways end with the minimisation of energy requirement and consumption, in order to reduce the external climate forcing which in turn will reduce the biodiversity extinction threat.

\section{REFERENCES}

1. Anonymous (2014). International Union for the Conservation of Nature; http://www.iucnredlist.org

2. Birdlife International (2014). Retrieved from http:// www.birdlife.org

3. Chandrakar A.K., Yadav K.K., Kumar V., Gupta N. (Sep., 2016). Scenario of biodiversity conservation in India: An overview, $1^{\text {st }}$ ed,. UBN - 015A94510112027

4. Dominique B. et al. (2010), The CC-Bio Project: Studying the effects of climate change on Quebec biodiversity, diversity, 2, 1181-1204; doi:10.3390/ d2111181

5. Done T. (2003). Coral reefs and global climate change: implications of changed temperatures, sea level, atmospheric carbon dioxide and cyclone regimes, Australian Institute of Marine Science (AIMS), Australia Global Climate Change and Biodiversity University of East Anglia, Norwich, UK

6. Figueres, C., C. Le Quéré, G. P. Peters, G. Whiteman, A. Mahindra, D. Guan, (2018). Emissions are still rising: ramp up the cuts. Nature, Retrieved from https://www.nature.com/articles/d41586-01807585-6

7. Frithjof C. Küpper and Nicholas A. Kamenos (2017). Foresight - Future of the Sea: Marine Biodiversity.
https://assets.puglishing.service.gov.uk/.../Future of the Sea- Marine Biodiversity

8. Hui (2013). Global Climate Change and Biodiversity: Issues and Future Research.

9. J. Biodivers Endanger Species, 1:2. Retrieved from http://dx.doi.org/10.4172/2332-2543.1000e105.

10.Jackson, R.B., C. Le Quéré, R. M. Andrew, J.G. Canadell, J.I. Korsbakken, Z. Liu, G.P. Peters, and B. Zheng (2018). Global Energy Growth Is Outpacing Decarbonization, Environmental Research Letters. https://doi.org/10.1088/1748-9326/aaf303

11.Jetz W., Wilcove D. S., Dobson A. P.(2007). Projected impacts of climate and land-use change on the global diversity of birds. PLOS Biol. 5: e157. doi: 10.1371/journal.pbio.0050157; pmid: 17550306

12.Jonathan Davies T. (2016). In: 1,2,7 Mark C. Urban,3 Bronwyn Rayfield, 1,4 Marc W. Cadotte,5 and Pedro R. Peres-Neto, Ecology, 97 (9) : 2212-2222

13.Le Quéré (2018) Global Carbon Budget (2018). Earth System Science Data. https://doi.org/10.5194/essd10-2141-2018

14.Malcolm J. R., Liu C., Neilson R. P., Hansen L., Hannah L. (2006). Global warming and extinctions of endemic species from biodiversity hotspots. Conserv. Biol., 20 538-548. doi: 10.1111/j.15231739.2006.00364.x; pmid : 16903114

15.Munasinghe M. (2010). Making Development more sustainable: Sustainomics Frame work and practical applications, $2^{\text {nd }}$ ed, Colombo: MIND Press, Munasinghe Institute for Development, URL: mindlanka.org

16.Munasinghe M. (2002). The sustainomics transdisciplinary meta-framework for making development more sustainable, UN World Summit on Sustainable Development (WSSD), Johannesburg, Int. J. Sust. Dev., 5:125-182

17.Munasinghe M. (2009). Sustainable development in practice, Sustainomics Methodology and Applications, Cambridge; Cambridge University Press

18.Parker L. M. et al. (2013) Predicting the response of molluscs to the impact of ocean acidification. Biology, 2: 651-692.doi: 10.3390/biology2020651

19.Pimm S. L.(2008), Biodiversity: Climate change or habitat loss- Which will kill more species? Curr. Biol., 18, R117-R119. doi: 10.1016/j.cub.2007.11.055; pmid : 18269905

20.Schipper J. et al. (2008). The status of the world's land and marine mammals: Diversity, threat, and knowledge. Science, 322 : 225-230 doi:10.1126/ science.1165115; pmid: 18845749

21.Sekercioglu C. H., Schneider S. H., Fay J. P., Loarie S. R.(2008), Climate change, elevational range shifts, and bird extinctions. Conserv. Biol., 22, 140-150.

22.Soni D.K. and Farid Ansari (2017). Climate change and biodiversity, impacts, vulnerability and mitigation in Indian perspective: A review. J. of Applied and Natural Science, 9(1), 632-638.

23.Stuart S. N., Chanson, J.S. , Cox, N.A. , Young, B. E., Rodrigues, A.S., Fischman, D. L., Waller, R.W.m (2004). Status and trends of amphibian declines and extinctions worldwide. Science, 306 : 1783-1786

24. Thomas C. D. (2004), Extinction risk from climate change. Nature, 427: 145-148. Van Vuuren D. P., Sala O. E., Pereira H. M.(2006), The future of vascular plant diversity under four global scenarios. Ecol. Soc., 11, 25-42. 